\title{
“NINGUÉM SABE DE NADA, NINGUÉM VIU NADA. TODOS CALADOS"
}

Raquel Alves Ishii ${ }^{1}$

NEPOMUCENO, Eric. Massacre - Eldorado dos Carajás: uma história de impunidade. 1ํa ed., São Paulo: Editora Planeta, 2007, 214p.

Einte e um anos de
vinter completou impunidade da matança ocorrida na tarde de 17 de abril de 1996, no trecho da rodovia PA-150, a poucos quilômetros de Eldorado dos Carajás, Estado do Pará. De lá pra cá, muito pouca ou quase nenhuma justiça foi feita diante das atrocidades cometidas contra dezenove trabalhadores sem-terra, mortos a sangue frio por policiais (civis e militares) e pistoleiros, e outras dezenas de feridos que, até hoje, carregam em seus corpos as lembranças físicas do atentado (posteriormente faleceram mais duas pessoas, em decorrência dos ferimentos sofridos).

Eric

Nepomuceno, jornalista, ensaísta, romancista, tradutor de autores contemporâneos da literatura hispânica como Jorge Luís Borges, Juan Rulfo e Garcia Márquez, escreve, ou melhor, descreve a 'carnificina brutal' ocorrida em Eldorado dos Carajás, em 1996. Seu livro, o Massacre - Eldorado dos Carajás: uma história de impunidade, é o resultado de uma colossal pesquisa das mais diversas fontes que vão desde as cinqüenta e quatro horas de gravações de áudio, incontáveis documentos acadêmicos e jornalísticos, até as quase vinte mil páginas dos dois inquéritos da Polícia Civil e Militar que "investigaram" o caso.

No livro, o autor apresenta dados e mais dados, além de testemunhos que abordam infinitas perspectivas históricas do massacre que, aos poucos, vão compondo um quebracabeça ensanguentado, numa consistente tentativa de, através

1 Mestre em Letras: Linguagem e Identidade - PPGLI/UFAC (2011) e professora da Universidade Federal do Acre, lotada no Centro de Educação, Letras e Artes. 
de seu olhar, oferecer aos leitores algo que Beatriz Sarlo (ao se referir às representações do holocausto no filme Shoah, de Claude Lanzmann) chamou de um monumento que lembra o horror. Um monumento que serve não apenas para intensificar a lembrança do horror, mas para "dificultar sua inevitável deterioração" (SARLO, 1997, p. 40) ou, em outras palavras, dificultar o nosso corrosivo esquecimento.

Numa proposta não linear de narrar os fatos e numa linguagem direta, Nepomuceno apresenta detalhes materiais do atentado: horários de chegada e saída de policiais militares da área do massacre; quantidade e tipos de armas e balas utilizadas pela polícia; posição dos corpos empilhados no caminhão que os levou ao necrotério; locais das perfurações com armas brancas e passagens dos tiros nos corpos das vítimas, além de uma infinidade de números que vão desde a extensão de terras no Estado do Pará, até os relatórios anuais das mortes no campo no Brasil, passando pela vergonhosa "indenização" que hoje recebem os sobreviventes.

Nepomuceno quer indignar e consegue. Não apenas por demonstrar a inoperância e contradições do Estado brasileiro através de suas instituições corrompidas pelo poder que exercem os latifundiários da região amazônica, muitos deles grileiros deterras que, com certa "influência" em determinados cartórios, acabam por conseguir os títulos de terras pertencentes à União, mas, principalmente porque quis o autor que todos soubessem através de seu texto que ele próprio não consegue conceber que a crueldade de determinados grupos de políticos, fazendeiros, grileiros, pequenos comerciantes e interessados apenas em seus rentáveis negócios oriundos da exploração do trabalho (muitas vezes, escravo) das gentes que habitam esse espaço, principalmente o Estado do Pará, pudessem ir tão longe e continuar impunes, à margem da Justiça. Justiça essa, a grande responsabilizada pelo autor 
por toda a tragédia pintada com sangue em seu livro, pois esta se desmembra, a depender dos envolvidos, em uma imposição de determinada lei e uma determinada ordem "cujos limites e parâmetros ninguém, a não ser os que as impõem, conhece".

O livro é dividido em cinco partes. Cada uma delas é introduzida por fotografias em preto e branco de impressionantes cenas das vítimas do massacre e da dor dos familiares.

$\mathrm{Na}$ imagem que introduz a primeira parte, uma vítima, inteiramente disforme e ensangüentada dentro de um caixão aberto, é identificada apenas por um pedaço de papel, também sujo de sangue, onde se lê: no 08 .

Nesta parte, o autor destina-se a expor uma legião de números que, segundo o próprio autor, chegam a 'marear' quem os lê, mas com o objetivo de tornar mais palpável ao leitor os fatos que (ainda) ocorrem na região amazônica. Dados espantosos oriundos dos estudos da Organização Internacional do Trabalho, Organização dos Estados Americanos - OEA, Movimentos dos Trabalhadores Sem-Terra MST e do Instituto Brasileiro de Geografia e Estatística - IBGE registram padrões de violência quase que permanente no campo em todo o Brasil - o que inclui os casos de trabalho escravo.

0 Estado campeão, que tem concentrado grande parte das ocorrências de conflitos de terra, tem sido o Estado do Pará apresentando um milhão e 260 mil quilômetros quadrados de terra, o que significa mais que o dobro do tamanho da França e mais que a Itália, Espanha e Alemanha juntas e com uma baixíssima densidade demográfica. Lá vivem cerca de seis milhões e 600 mil pessoas o que é pouco mais de um terço da população que vive na região da chamada 'Grande São Paulo', ou seja: lá, sobra terra, conclui o jornalista. Mesmo assim, a impunidade, violência e conflitos acirrados pela posse da terra são sinônimos 
da região. Segundo dados de relatório da Comissão Pastoral da Terra - CPT, entre os anos de 1985 e 2004 morreram no Brasil 1.399 trabalhadores rurais e somente no Pará, foram mortos 772 camponeses e ativistas dos direitos humanos, entre os anos 1971 e 2004 e, somente em 1996, ano do massacre em Eldorado dos Carajás, o Estado do Pará foi responsável por $72 \%$ dos assassinatos de trabalhadores rurais no país.

\section{Vila dos Mutilados}

Tendo composto o cenário macro da narrativa, Nepomuceno inicia a segunda parte do livro relatando a atual situação dos sobreviventes ao morticínio que, hoje moram numa vila batizada de 17 de Abril, localizada em terras da antiga fazenda Macaxeira, em Eldorado dos Carajás. Na foto que introduz esse capítulo, observa-se o caminhão que transportou os caixões empilhados um em cima do outro das 19 vítimas da tragédia de abril de 1996. Esse é o início do cortejo fúnebre que Nepomuceno nos obriga a participar e nele seremos também violentados ao acompanhar essas imagens.

'Mutilados': assim são conhecidos os 66 sobreviventes do atentado. Estigmatizados e sofrendo preconceitos de toda ordem pelos moradores mais recentes da Vila que, por sua vez, apenas existe por suas causas. Na realidade, os sobreviventes eram 69, mas três deles morreram três dias depois do massacre dado à extrema gravidade dos ferimentos.

Em uma série de exemplos que compõe o que o autor denomina de 'inventário dos padecimentos' acompanhamos os seguintes relatos:

Domingos da Conceição, o "Garoto", tinha 15 anos na tarde do horror. Levou mais de dez tiros, a maioria nas pernas. Sofreu deformações na bacia e nos ombros. Teve fratura exposta na perna direita, foi operado 11 vezes. A perna ficou três centímetros mais curta que a outra e dói sem parar. Nos dias de frio ou de chuva, a dor fica insuportável. Passados dez anos daquele abril de 1996, continuava esperando pelas botas ortopédicas prometidas pelo governo do estado para poder caminhar sem tanta dor (p.70). 
Rubenita Justiniano da Silva, no dia do massacre, tinha 26 anos. Levou um tiro na boca, teve a mandíbula fraturada, a língua rasgada, perdeu seis dentes, e a bala ficou para sempre alojada em sua garganta. Até 2003, continuava na Vila $17 \mathrm{de}$ Abril. Depois mudou-se com a mãe e a irmã menor para uma ilha vizinha a Belém. Com a freqüência das rotinas cruéis, sem aviso, o pescoço desanda a latejar; o local ferido inflama, os olhos ficam avermelhados, a visão enevoada (pp. 71-72)

Uma série de outros relatos se segue descrevendo com atordoantes detalhes a degradante situação que hoje ainda se encontram os que, contra todas as possíveis formas de agressões físicas, morais, materiais e psicológicas, sobreviveram à covardia de policiais militares no dia do massacre. Mais trágico ainda é saber que desses 66, somente 20 conseguiram, em 1998, entrar na Justiça solicitando indenização, tratamento médico e uma pensão do Estado do Pará. 0 restante, não conseguiu comprovar, com documentos, 'que sofreram o que sofreram'. Mesmo assim, para os 20 que entraram na Justiça, não foi simples enfrentar a burocracia e a ausência de vontade política do poder público. Tiveram que esperar até agosto de 2006, sete anos depois, para receberem a devida "justiça".

Outro ponto que chama atenção neste capítulo diz respeitoàs condições devidados moradores da Vila 17 de Abril. Existe um descontentamento generalizado em relação aos lotes dos assentados na área: sem as devidas condições de viver nela ou dela, não se é suficiente "dar" a terra. Muitas famílias já abandonaram suas áreas, passando por uma espécie de expulsão, um desterro, onde o sonho de poder viver da terra vai ficando cada vez menor, chegando até mesmo a desaparecer. A Vila é cercada pelos lotes do Assentamento, possui 19 ruas que partem de uma praça. Cada rua tem o nome de um dos assassinados. Sem saneamento básico e rede de abastecimento de água, cerca de 2.783 mil pessoas vêem a vida passar silenciosamente. A energia elétrica só chegou na 
Vila em 2002, depois de cinco anos de sua existência. Possui apenas uma escola que agrupa ensino médio e fundamental e leva o nome de Escola Municipal Oziel Alves Pereira, um dos líderes do movimento de 17 anos que, possivelmente, foi um alvo certo no dia do massacre. Atualmente, além de uma 'solitária igreja católica', na região há uma forte presença de igrejas evangélicas que, no início, "foram especialmente corrosiv[a]s na hora de minar a influência do MST sobre dos habitantes da Vila", mas hoje, a relação do Movimento com essas instituições parece convergir em prol da organização e da melhoria das condições de vida de seus moradores.

\section{Animus necandi}

A dor manifestada em imagem do desespero da mãe de Oziel Alves Pereira, durante a cerimônia fúnebre de seu filho em 20 de abril de 1996 é como o autor abre a terceira parte do livro, descrevendo com um rigor frio de detalhes - tendo em vista que a maioria das informações aqui apresentadas são retiradas de laudos de peritos do Instituto
Médico Legal de Marabá e de outros documentos oficiais que integraram os inquéritos policiais do caso - o estado e a causa das mortes dos 19 semterra:

As mortes dos integrantes do MST não resultaram do confronto. A perícia técnica, robustecida pela prova testemunhal, autoriza a constatação de uma desmedida e injustificada execução sumária por tiros de precisão, inclusive à queima roupa, por corpos retalhados a golpes de instrumentos cortantes, inclusive com esmagamento de crânio e mutilações que evidenciam o animus necandi dos executores da ação criminosa (pp. 111-112)

Animus necandi, o próprio autor explica: vontade de matar. Esse trecho é retirado do parecer final relativo ao julgamento dos policiais. $\mathrm{Ou}$ seja, mesmo considerando as inúmeras manobras para burlar os procedimentos regulares de investigação do crime, procedimentos estes que vão desde o controle da entrada e saída do armamento utilizado pela polícia no dia da matança até a recusa, sem justificativa aceitável, de vários 
juízes de levarem o julgamento dos policiais adiante, tornouse impossível negar, como demonstra a própria e vasta documentação oficial, que o que ocorreu naquela tarde fora um dos maiores atentados ao direito à vida registrado no país.

No entanto, a escada de sangue parece não ter fim, pois o fato é que, não bastou um ou dois tiros para matar, por mais repugnante que seja escrever isso. 0 autor relata que testemunhas afirmaram que um dos responsáveis pelo comando de 68 homens da Polícia Militar que estiveram presentes na chacina, o major José Maria Oliveira, ainda disparou dois tiros de um revolver calibre 38 em Oziel Alves Pereira quando este já estava no chão, após ter levado um tiro na nuca. Da mesma forma aconteceu com José Ribamar Alves de Souza (22 anos): "os tiros que o mataram foram disparados a queima-roupa. (...) Ele estava no chão quando foi atingido. Levou mais dois tiros no peito". Além dos tiros, observou-se pelas fotos tiradas dos corpos que mutilações de todas as ordens foram feitas através de golpes de punhais, facões ou foices. No total eram 180 homens entre policiais e "auxiliares de seguranças" de certos fazendeiros e comerciantes locais. Dentre esses homens, 85 estavam sob o comando do coronel Mario Colares Pantoja, autor da "célebre" frase que dá título a este artigo, quando, após o massacre, ao entrar no ônibus de volta para a cidade de Marabá, teria dito a todos os seus subordinados em voz alta: "Ninguém sabe de nada, ninguém viu nada. Todos calados". O coronel Pantoja foi condenado a 228 anos de cadeia. Foi solto em setembro de 2005. Assim como ele, o major Oliveira foi sentenciado a 158 anos de prisão. Foi solto dias depois de seu comparsa, o coronel Pantoja. Até hoje, a história de impunidade continua.

\section{Início da História: erro de cálculo}

Igreja de Curionópolis: velório das vítimas de Eldorado dos Carajás. Centenas de pessoas aparecem ao redor 
dos caixões na imagem que inicia a penúltima parte do livro de Nepomuceno. Aqui, numa digressão, o autor relata o início de toda a história, quando na década de 1990 o MST intensificava sua atuação na região sul do Estado do Pará, ao ponto de em 1995, cerca de 10 mil sem-terra ocuparem a fazenda Macaxeira na cidade Eldorado dos Carajás.

Aqui residiu, na opinião do autor, o erro de cálculo por parte dos dirigentes do MST, visto que seu grande poder de mobilização massiva e até de intimidação das "autoridades" locais acabou por guiar seus dirigentes a uma avaliação equivocada da repercussão desse movimento. Não perceber a fúria desmedida que estava sendo cultivada na região por conta dessas ações e acreditar que podiam reunir condições para radicalizar o movimento foi um erro reconhecido mais tarde pelo próprio MST. A falha iria se agravar ainda mais, segundo Nepomuceno, devido ao fato de não terem considerado uma mudança radical no conflito entre os grandes proprietários de terra e os sem-terra: ao invés de contratar jagunços ou os chamados pistoleiros para "darem cabo" das lideranças do movimento, os latifundiários dispunham agora de uma, digamos, milícia particular: a Polícia Militar e/ou Civil proteção garantida em troca de um "apoio logístico" mensal.

Em meio às tensões extremadas oriundas dos firmes posicionamentos do MST nas mesas de negociações com o INCRA e com o Governo do Estado através do Instituto de Terras do Estado do Pará ITERPA, acusados de fraudar os laudos ditos "técnicos" da área naquele momento ocupada pelo MST, este decidiu ocupar uma área da prefeitura de Curionópolis. No dia 08 de abril de 1996, um grupo de mais de mil ocupantes acamparam em um posto de gasolina abandonado. E foi então que os ocupantes decidiram anunciar a radicalização do movimento: uma marcha até Marabá, sede do INCRA, para uma reunião com seu superintendente, 
Walter Cardoso, e então seguir até Belém, ou seja, uma andança de mais de 812 quilômetros até a capital do Estado.

Para consolidar o ato, que logo teria repercussão nacional, os dirigentes do MST se arrastavam em negociações com o INCRA e com o Governo do Estado pedindo dez toneladas de comida e sandálias para as mulheres, homens e crianças que seguiriam marchando.

Nada de acordo.

Assim, na véspera do início da marcha, dia 09 de abril de 1996, um grupo de sem-terra decidiu bloquear a estrada entre Curionópolis e Marabá, e saquearam um caminhão de suprimentos. Com o saque puderam armazenar quase 16 toneladas de comida e todas as sandálias disponíveis, o que, obviamente, aumentou a ira do prefeito e dos comerciantes da região. Por toda a cidade comentava-se que haveria uma reação dos fazendeiros que pressionavam cada vez mais o governador do estado do Pará, a época Almir Gabriel (PSDB), para que resolvesse a situação que estava se aproximando de seu limite.

Às oito horas da noite do dia 10 de abril, à luz de tochas, 4.221 pessoas deram início à marcha. Em cinco horas caminharam 12 quilômetros em um clima de euforia. Chegaram a Eldorado dos Carajás, no dia 15 de abril ao final da tarde. Foram 40 quilômetros percorridos em cinco dias. Nesse ritmo, levariam cem dias para chegar a Belém. A esta altura apenas dois terços do total de caminhantes continuavam a marcha. O MST descobriria logo a grande problemática de organizar tanta gente: desidratação, desmaios e doenças outras sem muita gravidade. Mulheres e crianças foram enviadas de volta a Curionópolis.

$\mathrm{Na}$ manhã do dia 16 de abril os ocupantes acamparam na Curva do $\mathrm{S}$, no sentido Marabá-Eldorado e negociavam o envio de comida. No entanto, um dia antes já havia sido dada a ordem de dispersar a marcha: sem negociações.

No pico das tensões no final do dia 16, terça-feira, 
os ocupantes bloquearam a rodovia PA-150, a Curva do S. Exigindo comida e transporte para que pudessem continuar a viagem, os manifestantes deram um prazo ao Governo do Estado para que suas reivindicações fossem atendidas: às doze horas do dia 17 de abril.

Nada feito.

Por volta das quatro e meia da tarde, explosões de bombas de gás lacrimogêneo e os primeiros tiros oriundos da tropa de militares comandada pelo Coronel Pantoja deram início ao caos.

Quarenta minutos. Foi o tempo que levaram para "liberar" a estrada "obstruída" por 2.500 manifestantes. Os corpos foram empilhados na caçamba de uma caminhonete D-20 e levados para a cidade de Curionópolis. No local do massacre, tudo havia sido removido, sem pistas ou feridos. Nada para investigar. Dias depois surge na imprensa nacional o valor da morte dos sem-terra: mais de cem mil reais. A denúncia surgiu de uma entrevista com um fazendeiro anônimo publicado na Folha de S. Paulo de 10 de maio de 1996. O dinheiro teria sido arrecadado entre os fazendeiros da região e entregue ao coronel Mário Pantoja. 0 fazendeiro revelou ainda que cerca de seis pessoas teriam sido mortas após o massacre como queima de arquivo, os corpos nunca foram encontrados.

\section{Não admitir a impunidade}

No desfecho do livro, quinta parte, acompanhamos o funeral das vítimas, imagem desoladora que inclusive é capa do livro, fechando, assim, o ciclo sem fim da impunidade.

Os verdadeiros mandantes da ação criminosa da tarde de 17 de abril - o governador Almir Gabriel (PSDB), o Secretário de Segurança Pública Paulo Sette Câmara e o Comandante Geral da Polícia Militar do Estado do Pará, coronel Fabiano Lopes, sequer foram indiciados. As investigações sobre suas responsabilidades no massacre foram suspensas e arquivadas pelo Supremo Tribunal Federal.

Entre os que participaram diretamente do extermínio 
dos sem-terra, 155 policiais foram levados a julgamento. Somente no ano de 2002, Roberto Moura foi designado o terceiro e último juiz a pegar o caso, tendo em vista as aberrantes parcialidades em favor dos policiais dos dois juízes anteriores. 0 primeiro juíz, inclusive, teve seu julgamento anulado por ter considerado inocentes o Coronel Pantoja e o Major Oliveira. Imediatamente após tal anulação, 17 juízes da vara criminal da comarca de Belém comunicaram oficialmente ao Presidente do Tribunal de Justiça que não aceitariam presidir novo julgamento, pois eram favoráveis aos policiais militares.

Em uma "distinta demonstração de eficácia" no trato da coisa pública, o juíz Roberto Moura, em uma única sessão, julgou nada mais nada menos do que 128 acusados. À promotoria coube exatamente um minuto para apresentar provas da participação de cada um deles.

No total, foram cinco sessões nas quais se julgou o destino de 144 policiais militares. Dois deles - e apenas dois, o coronel Pantoja e o major Oliveira - foram condenados. Todos os outros, entre os quais estavam os assassinos de 19 sem-terra, foram declarados inocentes ( $p$. 203).

Hoje, vinte e um anos depois do atentado em Eldorado dos Carajás, os responsáveis pelo crime contra trabalhadores da terra permanecem em liberdade.

Embora os tons e nuances fatalistas destes escritos deixem transparecer algo de trevas ou de trágicos niilismos nesse campo de luta pela terra, pelo direito à moradia, ao trabalho e à vida, embora finalize esses escritos sem esperanças diante da impunidade, da (in)Justiça e de um Estado que cercam, desapropriam, expurgam, condenam ao exílio em seu próprio país e literalmente "apagam" os registros materiais da existência de centenas de trabalhadores rurais todos os anos no Brasil, Eric Nepomuceno nos lembra das dezenove cruzes que permanecem plantadas nos cemitérios de 
Curionópolis, Parauabepas, Marabá e Eldorado do Carajás, como que em um berro dado bem perto dos ouvidos de cada leitor seu, para que paremos todos de obedecer às ordens do coronel Pantoja, um dos maiores criminosos de farda que já existiu na Amazônia brasileira, que é de fecharmos os olhos, esquecermos de tudo e ficarmos calados.

Nunca teremos dimensões concretas do que passaram as pessoas que estavam na Curva do $\mathrm{S}$, às dezesseis horas daquela quarta-feira, 17 de abril de 1996, em Eldorado dos Carajás, Estado do Pará. Porém, Sarlo nos ensina que nos resignarmos a 'saber menos' é aceitar a possibilidade de esquecer, posto que tal 'saber parcial' é inimigo da memória (SARLO, 1997, p. 42). Ir a fundo nessa e em tantas histórias de impunidade pelas quais passaram essas mulheres, homens e crianças, sejam do campo ou da cidade, é forma não tanto de evitá-las, mas de não nos permitirmos à renúncia do direito de cidadania que quiseram dizimar junto com a morte dos sem-terra de Eldorado dos Carajás.

Em síntese, num arremate, que se nega a esquecer o que ocorreu, Nepomuceno escreve: "Na memória brasileira, essa ferida não termina de cicatrizar".

\section{Referências}

NEPOMUCENO, E. Massacre - Eldorado dos Carajás: uma história de impunidade. São Paulo: Editora Planeta, 2007.

SARLO, B. Paisagens imaginárias: intelectuais, artes e meios de comunicação. São Paulo: Edusp, 1997.

Data de recebimento: 22/07/2017 Data de aceite: 11/11/2017 